\title{
Growth of different infectious bursal disease virus strains in cell lines from origin of lymphoid leukosis tumors
}

\author{
Ahmed Hassan ${ }^{1,2,{ }^{*}, \text { Mostafa Shahata }}{ }^{2}$, Elrefaie Refaie ${ }^{2}$, Ragab Ibrahim ${ }^{2}$, Jun Sasaki ${ }^{1}$, \\ Masanubu Goryo ${ }^{1}$ \\ ${ }^{1}$ Department of Veterinary Pathology, Faculty of Agriculture, Iwate University, 3-18-8, Ueda, Morioka, 020-8550, Japan \\ ${ }^{2}$ Department of Poultry diseases, Faculty of Veterinary Medicine, Assiut University, Assiut, 71526, Egypt
}

\section{Email address:}

khalaf_poultry@yahoo.com (A. Hassan)

\section{To cite this article:}

Ahmed Hassan, Mostafa Shahata, Elrefaie Refaie, Ragab Ibrahim, Jun Sasaki, Masanubu Goryo. Growth of Different Infectious Bursal Disease Virus Strains in Cell Lines from Origin of Lymphoid Leukosis Tumors. Animal and Veterinary Sciences.

Vol. 3, No. 2, 2015, pp. 46-50. doi: 10.11648/j.avs.20150302.13

\begin{abstract}
Abstrac: Growth and propagation of infectious bursal disease virus (IBDV) in chicken embryo is time consuming and costly, and an appropriate serological test is required to detect and identify IBDV strains, therefore, a suitable cell lines in which different IBDV strains can grow well has been needed. The aim of the present work was to study the growth of different IBDV strains in cell lines from lymphoid leukosis tumors using histopathological staining, indirect immunofluorescence, immunohistochemistry and transmission electron microscopic examination. In conclusion, cell lines from origin of lymphoid leukosis tumors; LSCC-BK3 and LSCC-CU10 are suitable for growth and propagation of different IBDV strains. IBDV strains resulted into histopathological lesions of variable severity differ according to the patho-type of IBDV and time after virus inoculation. Indirect immunofluorescent test could be used for detection and differentiation of IBDV strains inoculated into cell lines from origin of lymphoid leukosis tumors. Trials of immunohistochemistry technique for detection of different IBDV strains in cell lines, were unsuccessful. Using transmission electron microscopy, IBDV particles could be detected in all infected cell lines.
\end{abstract}

Keywords: Infectious Bursal Disease Virus, Cell Lines, Histopathological Staining, Immunohistochemistry, Immunofluorescence

\section{Introduction}

Infectious bursal disease (IBD) was first described in 1962 [2]. IBD is one of the most economically important diseases that affect chickens and it possesses a great threat to the poultry industry worldwide [9].The economic importance of the disease is manifested in two ways. Firstly, some virus strains may cause mortalities up to $30 \%$ or more in three to six weeks old birds [9]. Secondly, and very importantly, the manifestation of severe, prolonged immunosuppression in chickens infected at early age and which have recovered [29].The immunosuppression increases the risk of secondary infection and reduces antibody response to vaccinations [21].The etiological agent of IBD is a double stranded RNA virus which is nonenveloped and icosahedral in symmetry
[13]. The virus is resistant to ether and chloroform, to extremes of $\mathrm{PH}$, high temperatures and some disinfectants, which is why the viral particles persist in poultry farms [16]. The disease is seen mostly in chickens between 3 to 6 weeks old, and common signs will include rapid drop in feed and water consumption, whitish to greenish-white diarrhea with soiled vent, ruffled feathers and listlessness with unsteady gait or sitting in hunched position, vent picking and sleeping with beak touching the floor. IBD virus primarily affects the bursa of Fabricius, resulting in inflammation and swelling and leading to damage of the organ with consequent immunosuppression [26]. Biosecurity measures and proper vaccinations are used in the control of IBD [30]. 
Table (1). Results of histopathological changes in different cell lines at different intervals after infection with different four IBDV strains.

\begin{tabular}{|c|c|c|c|c|c|c|c|c|c|c|}
\hline \multirow[t]{3}{*}{$\mathrm{DPI}^{\mathrm{a}}$} & \multicolumn{10}{|c|}{ Cell lines/Strains } \\
\hline & \multicolumn{2}{|l|}{993} & \multicolumn{2}{|l|}{ JI } & \multicolumn{2}{|l|}{ BDA } & \multicolumn{2}{|l|}{$\mathrm{Ni}$} & \multicolumn{2}{|l|}{ control } \\
\hline & Lscc-cu10 & Lscc-bk3 & Lsce-cu10 & Lscc-bk3 & Lscc-cu10 & Lsce-bk3 & Lsce-cu10 & Lscc-bk3 & Lscc-cu10 & Lscc-bk3 \\
\hline 1 day & + & + & + & + & - & - & - & - & - & - \\
\hline 2 days & ++ & ++ & ++ & ++ & + & + & + & + & - & - \\
\hline 3 days & +++ & +++ & +++ & +++ & ++ & ++ & ++ & ++ & - & - \\
\hline
\end{tabular}

${ }^{\mathrm{a}}$ Days post-inoculation

(-) Non visible, $(+)$ mild, $(++)$ moderate, $(+++)$ sever.

BDA: IBDV- BDA strain (Vaccine I strain), Ni: Nisseiken strain (Vaccine I strain)

Detection and identification of IBDV strains have been performed in chick embryos [8] because IBDV does not grow well in cell cultures originating from chickens or other animals $[15,23]$. Examination of IBDV in chicken embryo is time consuming and costly, and an appropriate serological test is required to detect and identify IBDV strains, so it is impossible to examine many viral samples at once when using chicken embryo [31]. Therefore, a suitable cell lines in which different IBDV strains can grow well has been needed.

It was reported that LSCC-CU 10 line cells derived from a lymphoid leukosis tumor was susceptible to IBDV [6]. It was concluded that LSCC-BK3 line was more susceptible to IBDV and could be used for detection and identification of the virus [31].

The aim of the present work was to study the growth of different IBDV strains in cell lines from lymphoid leukosis tumors using histopathological staining, indirect immunofluorescence, immunohistochemistry and transmission electron microscopic examination.

\section{Materials and Methods}

\subsection{Cell lines and IBDV Strains}

Established cell lines; LSCC-BK3, which originated from lymphoid leukosis lymphomatous bursa [5] and LSCC-CU10, which originated from lymphoid leukosis transplant TLT [1], were used for growth and propagation of IBDV strains; Very virulent IBDV 993 strain [4], moderately virulent IBDV J1 strain [31], Vaccine strain I: IBDV-BDA vaccine strain (Embrex Inc., Japan) and Vaccine strain II: Nisseiken vaccine strain (Nisseiken Co. Ltd, Japan). The growth medium for cell lines consisted of nutrient mixtures RPMI-1640 (Nisssuri) supplemented with $10 \%$ fetal bovine serum, $0.15 \%$ dehydrated tryptose phosphate broth (Difco), 100 units of penicillin, and $0.1 \mathrm{mg}$ of streptomycine per $\mathrm{ml}$.

\subsection{IBD Virus Inoculation into Cell Lines and Samples Collection}

$1 \mathrm{ml}$ from each IBDV strains was centerifugated at 104 RPM for 5 minutes and $0.5 \mathrm{ml}$ of supernatant was mixed with $4.5 \mathrm{ml}$ of growth mixture and then filtered using cellulose filter in petri dishes. $1 \mathrm{ml}$ from each cell line containing $5 \mathrm{x}$ 105 was added to each petri dish. Control cell lines without virus inoculation were prepared. All cell lines were incubated at $37^{\circ} \mathrm{C}$ with $5 \% \mathrm{CO} 2$ for 3 days. $1 \mathrm{ml}$ from each petri dish, including IBDV inoculated and control cell lines, was collected at 1, 2, and 3 days post inoculation, then centerifugated at 1.24 RPM for 5 minutes and discard supernatant then the washed 3 successive times with phosphate buffer saline (PBS). Slides were prepared from collected cell line samples then used for histopathology, indirect immunoflurocsence, and immunohistochemistry.

\subsection{Histopathology}

Slides which prepared from collected cell line samples at 1 , 2 , and 3 days post inoculation were fixed using acetone then deparaffinized in xylene, rehydrated by passing through descending grades of ethyl alcohol to distilled water, and stained by hematoxylin and esosin, mounted with neutral balsam. The stained sections were observed under microscope for assessing histopathological changes. The severity of histological lesions was scored as non visible $(-)$, mild $(+)$, moderate $(++)$ or sever $(+++)$.

\subsection{Indirect Immunoflurocsence}

Slides which prepared from collected cell line samples at 1 , 2 , and 3 days post inoculation were fixed using acetone then deparaffinized and hydrated. Cell line sections were covered with $0.1 \%$ trypsin $\mathrm{Ca}$ (antigen retrieval) for one hour at $37^{\circ} \mathrm{C}$. Sections were incubated with polyclonal chicken anti serum to IBD virus $(1 / 10)$ overnight at $4{ }^{\circ} \mathrm{C}$ in a humidified chamber. After being rinsed three times for 5 min each with TBS, the sections were incubated with Fluorescein isothiocyanate (FITC)-labeled secondary antibody (1/200) for 30 minutes at $37^{\circ} \mathrm{C}$. After a rinse with TPS, the sections were mounted. The procedure for negative control sections was the same as described above except the primary antibodies were substituted with PBS. The immunofluorescence results was scored as none visible $(-)$, mild $(+)$, moderate $(++)$ or sever $(+++)$.

\subsection{Immunohistochemistry}

Slides which prepared from collected cell line samples at 1 , 2 , and 3 days post inoculation were fixed using acetone then deparaffinized and hydrated. Cell line sections were covered with $0.1 \%$ trypsin $\mathrm{Ca}$ (antigen retrieval) for one hour at $37^{\circ} \mathrm{C}$. The endogenous peroxidase activities were removed with $1 \%$ $(\mathrm{v} / \mathrm{v})$ hydrogen peroxide $(\mathrm{H} 2 \mathrm{O} 2)$, and the non-specific binding sites were blocked by $10 \%$ normal goat serum for 20 minutes at room temperature. Sections were incubated with polyclonal chicken anti serum to IBD virus $(1 / 10)$ overnight at $4{ }^{\circ} \mathrm{C}$ in a humidified chamber. After being rinsed three times for $5 \mathrm{~min}$ 
each with TBS, the sections were incubated with peroxidase-labeled rabbit anti-chicken $\operatorname{IgG}(1 / 200)$ for 30 minutes at $37{ }^{\circ} \mathrm{C}$. After a rinse with TPS, the sections were reacted for 4 minutes with $0.02 \%(\mathrm{w} / \mathrm{v}) 3,3$-diaminobenzidine (DAB)-4HCL and $0.001 \%(\mathrm{v} / \mathrm{v}) \mathrm{H} 2 \mathrm{O} 2$ in $100 \mathrm{mM}$ distilled water, Subsequently, the sections were counterstained with hematoxylin and dehydrated and mounted. The procedure for negative control sections was the same as described above except the primary antibodies were substituted with PBS. The immunohistochemical lesions was scored as none visible (-), mild $(+)$, moderate $(++)$ or sever $(+++)$.

\subsection{Transmission Electron Microscopic Examination}

Cell line samples which collected at 1, 2, and 3 days post inoculation were fixed using $25 \%$ glutaraldehyde for 1 day then washed 3 times with PBS and incubated at $4{ }^{\circ} \mathrm{C}$ for 1 day. Cell line samples were post-fixed using $1 \%$ osmic acid for 2 hours and then dehydrated and replaced using ascending grades of ethyl alcohol, butyl-glycidyl ether (QY-1), QY-1 + Epon, and Epon. Cell line samples were embedded in Epon at $60{ }^{\circ} \mathrm{C}$ for 3 days. Epon embedded blocks were trimmed to expose cell line samples then roughly sectioned using glass knife and stained by toluidine blue. Thin sections $(0.5 \mu \mathrm{m})$ were cut using platinum knife and then sliced and mounted on sheet mesh. Samples were stained with both uranium acetate and lead salt aqueous solution. The stained cell line sections were observed under transition electron microscope for detection virus particles.

\section{Results}

\subsection{Histopathology}

Results of histopathologic staining are shown as lesion scores in table (2).

Table (2). Results of indirect immunofluroscence technique of various cell lines at different intervals following inculation with different IBDV strains.

\begin{tabular}{|c|c|c|c|c|c|c|c|c|c|c|}
\hline \multirow[t]{3}{*}{ DPI $^{a}$} & \multicolumn{10}{|c|}{ Cell lines/Strains } \\
\hline & 993 & & JI & & BDA & & $\mathbf{N i}$ & & control & \\
\hline & Lscc-cu10 & Lscc-bk3 & Lscc-cu10 & Lscc-bk3 & Lscc-cu10 & Lscc-bk3 & Lscc-cu10 & Lscc-bk3 & Lscc-cu10 & Lscc-bk3 \\
\hline 1 day & + & + & - & - & - & - & - & - & - & - \\
\hline 2 days & ++ & + & + & + & - & - & - & - & - & - \\
\hline 3 days & ++ & ++ & + & + & + & + & + & + & - & - \\
\hline
\end{tabular}

${ }^{a}$ Days post-inoculation

$(-)$ Non visible, $(+)$ mild, $(++)$ moderate, $(+++)$ sever.

BDA: IBDV- BDA strain (Vaccine I strain), Ni: Nisseiken strain (Vaccine I strain)

No histological changes were observed in control cell lines, whereas other infected cell lines with each of the four strain of IBDV showed degeneration and necrosis of lymphocytes as shown in figure (1).

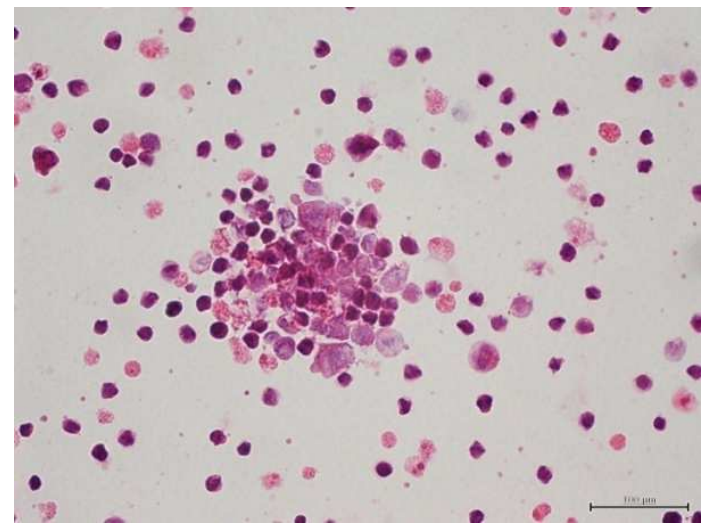

Figure (1). Histopathology, LSCC-CU10 cell line infected with vvIBDV 993 strain 3 days post infection, showing degeneration and necrosis of lymphocytes, (magnification 40X).

It was observed that histological changes in cell lines increased in severity with the time post inoculation. It was recorded that vvIBDV (993) strain resulted in lesion scores similar to virulent (J1) strain, while both vaccine strains resulted into similar lesion scores which are less in severity than vvIBDV and virulent strains.

\subsection{Indirect Immunofluorescence}

Indirect immunofluorescence technique was used to detect viral antigen of IBDV in LSCC-CU10 and LSCC-BK3 cell lines infected with 993 (vvIBDV), J1 (moderately virulent IBDV) and vaccine strains of IBDV. Results revealed that IBDV antigen could be detected abundantly, moderately and rarely in cell lines infected with 993, $\mathrm{J} 1$ and vaccine strains of IBDV, respectively at 1,2 and 3 days post inoculation as shown in table (2). The positive reaction for immunofluorescense in cell lines appears as immunofluoresent green color [Figure (2)].

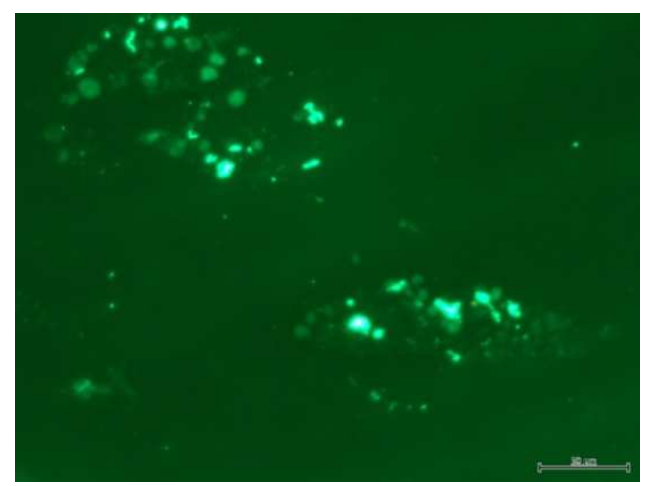

Figure (2). Immunofluorescence, fluoresent antigens in cytoplasm of the LSCC-BK3 cell line infected with vvIBDV 993 strain 3 days post infection (magnification 40X), the viral antigen appears as immunofluoresent green color. 
Control cell lines showed negative results for immunofluorescence technique.

\subsection{Immunohistochemistry}

Immunohistochemistry technique was used to detect viral antigen of IBDV in LSCC-CU10 and LSCC-BK3 cell lines infected with 993 (vvIBDV), J1 (moderately virulent IBDV) and vaccine strains of IBDV. Results revealed that trials of immunohistochemistry technique for detection of different IBDV strains in cell lines, were unsuccessful.

\subsection{Transmission Electron Microscopic Examination}

Transmission Electron Microscopic examination was used to detect viral antigen of IBDV in LSCC-CU10 and LSCC-BK3 cell lines infected with 993 (vvIBDV), J1 (moderately virulent IBDV) and vaccine strains of IBDV. Results revealed that IBDV particles could be detected in all infected cell lines at 2 days post infection. IBDV particles 62 $\mathrm{nm}$ in diameter were recognized in the cytoplasm of infected cells by electron microscopy as shown in figure (3).

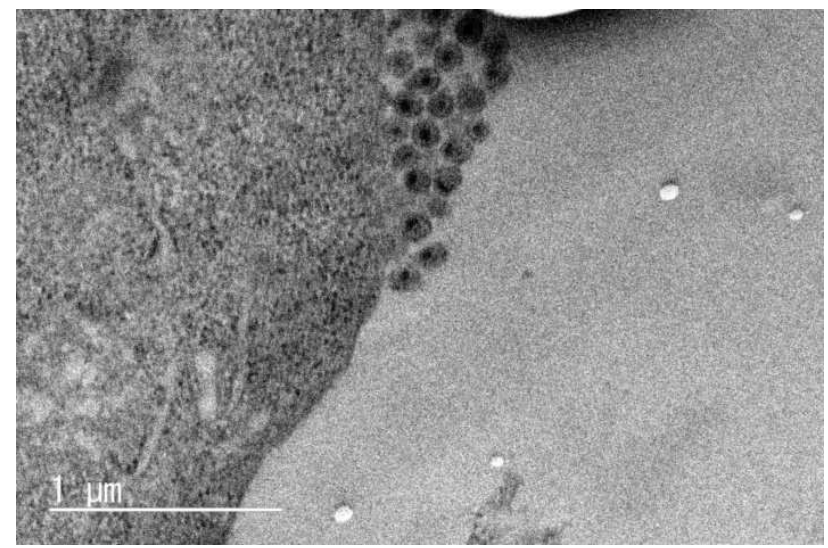

Figure (3). Transmission Electron Microscopy, electron micrograph of LSCC-CU10 cell line infected with moderately virulent J1 strain 2 days post infection, clusters of virus particles are seen in cytoplasm (magnification $100,000 X)$.

No virus particles were detected in control cell lines.

\section{Discussion}

IBDV has been successfully adapted to cell lines originated from chicken embryo, including chicken embryo bursal cells, kidney cells, and fibroblast cells [3, 15, 20, 25, 27]. IBDV also has been propagated on cell cultures including turkey and duck embryo cells [20], mammalian cell lines derived from rabbit kidneys [24], Vero cells [7, 10, 17], derived from African green monkey kidneys; BGM-70 cells [10], derived from givet monkey kidneys; and MA-104 cells [10] from fetal rhesus monkey kidneys. IBDV may be adapted to cell line, but isolation and propagation of some IBDV strains may be difficult with this technique [14, 19, 22, 25, 28]. Results of our study indicated that cell lines from origin of lymphoid leukosis tumors including LSCC-BK3 and LSCC-CU10 are suitable for growth and propagation of different IBDV strains.
Our research scored the severity of histological lesions in these cell lines 1,2 and 3 days post inoculation with different IBDV strains and results revealed that cell lines showed degeneration and necrosis of cells with variable severity differ according to the patho-type of IBDV and time after virus inoculation. It was observed that histological changes in cell lines increased in severity with the time post inoculation. It was recorded that vvIBDV (993) strain resulted in lesion scores similar to virulent (J1) strain, while both vaccine strains resulted into similar lesion scores which are less in severity than vVIBDV and virulent strains.

Indirect mmunoflorescence technique [18] and electron microscopic examination [20] of the infected cell line or embryonating eggs are suitable methods for observation the growth and propagation of IBDV. It is possible to grow IBDV in transformed cell lines $[6,11,12,13,15,31]$. In the present study, indirect immunofluorescence technique was used to detect viral antigen of IBDV in LSCC-CU10 and LSCC-BK3 cell lines infected with 993 (vvIBDV), J1 ( moderately virulent IBDV) and vaccine strains of IBDV. Results revealed that IBDV antigen could be detected abundantly, moderately and rarely in cell lines infected with 993, J1 and vaccine strains of IBDV, respectively at 1,2 and 3 days post inoculation. In our study, transmission electron microscopic examination was used to detect viral antigen of different IBDV in the same cell lines and results indicated that IBDV particles could be detected in all infected cell lines at 2 days post infection. IBDV particles $62 \mathrm{~nm}$ in diameter were recognized in the cytoplasm of infected cells by electron microscopy.

Trials of immunohistochemistry technique were used to detect viral antigen of IBDV in LSCC-CU10 and LSCC-BK3 cell lines infected with 993, J1 and vaccine strains of IBDV, but results reported that all these trials, were unsuccessful. Further studies are required to understand why immunohistochemistry is unable to detect IBDV in infected cell lines.

In conclusion, Cell lines from origin of lymphoid leukosis tumors; LSCC-BK3 and LSCC-CU10 are suitable for growth and propagation of different IBDV strains. IBDV strains resulted into histopathological lesions of variable severity differ according to the patho-type of IBDV and time after virus inoculation. Indirect immunofluorescent test could be used for detection and differentiation of IBDV strians inoculated into cell lines from origin of lymphoid leukosis tumors. Trials of immunohistochemistry technique for detection of different IBDV strains in cell lines, were unsuccessful. Using transmission electron microscopy, IBDV particles could be detected in all infected cell lines.

\section{Acknowledgments}

The authors would like to thank the stuff members of laboratory of Veterinary Pathology, Iwate university for their help to finish this work. The authors acknowledge the financial support of Egyptian government represented by Ministry of higher education scholarship. 


\section{References}

[1] Calnek, BW, Murthy, KK and Schat, KA. Establishment of Marek's disease lymphoblastoid cell lines from transplantable versus primary lymphomas. Int J Cancer 1978; 21: 100-107.

[2] Cosgrove, AS. An apparently new disease of chickens - avian nephrosis. Avian Dis 1962; 6: 385-389.

[3] Eterradossi, N and Saif, YM. Infectious Bursal Disease. In Saif, YM, Fadly, AM, Glisson, JR, McDougald, LR, Nolan, LK and Swayne, DE, editors. Diseases of Poultry, 12th ed, Ames, Iowa, USA: Blackwell Publishing Professional; 2008, p. 185-208.

[4] Goryo, M. Experimental study of very virulent infectious bursal disease virus (vvIBDV). Avian Dis 1992; 36: 13-22.

[5] Hihara, H, Yamamato, H, Arai, K, Okazaki, W and Shimizu, T. Conditions for successful cultivation of tumor cells from chickens with avian lymphoid leukosis. Avian Dis 1980; 24: 971:979.

[6] Hirai, K and Calnek, BW. In vitro replication of infectious bursal disease virus in established lymphoid cell lines and chicken B lymphocytes. Infect Immun 1979; 25: 964-970.

[7] Hirai, K. and Shimakura, S. Structure of infectious bursal disease virus. J Virol 1974; 14: 957-964.

[8] Hitchner, SB. Infectivity of infectious bursal disease virus for embryonating eggs. Poult Sci 1970; 49: 511-516.

[9] Hussain, I, Rasool, MH and Mahmood, MS. Production of hyperimmune serum against infectious bursal disease virus in rabbits. Pak Vet J 2004; 24: 179-183.

[10] Jackwood, DH, Saif, YM and Hughes, JH. Replication of infectious bursal disease virus in continuous cell lines. Avian Dis 1987 ; $31: 370-375$.

[11] Kibenge, FSB, Dhillon, AS and Russell, RG. Growth of serotypes I and II and variant strains of infectious bursal disease virus in vero cells. Avian Dis 1988; 17: 298-303.

[12] Kibenge, FSB, Dhillon, AS and Russell, RG. Biochemistry and immunology of infectious bursal disease virus. J Gen Virol 1988; 69: 1757-1775.

[13] Kibenge, FSB, McKenna, PK and Dybing, JK. Genome cloning and analysis of the large RNA segment (segment A) of a naturally avirulent serotype 2 infectious bursal disease virus. Virology 1991; 184: 437-40.

[14] Lee, LH and Lukert, PD. Adaptation and antigenic variation of infectious bursal disease virus. J Chin Soci Vet Sci 1986; 12: 297-304.

[15] Lukert, PD. and Davis, RB. Infectious bursal disease virus: growth and characterization in cell cultures. Avian Dis 1974; 18: $243-250$.

[16] Lukert, PD and Saif, YM. Infectious bursal disease virus. In: Calnek, BW, Barnes, HJ, Beard, CW, Mc Dougald, LR and Saif, YM, editors. Diseases of Poultry, 10th ed. Ames, Iowa, USA: Iowa State University Press; 1997, p.721-738.
[17] Lukert, PD, Leonard, J and Davis, RB. Infectious bursal disease virus: Antigen production and immunity. Am J Vet Res 1975; 36: 539-540.

[18] MacDonald, RD. Immunofluorescent detection of double-stranded RNA in cells infected with reovirus, infectious pancreatic necrosis virus, and infectious bursal disease virus. Can J Microbiol 1980; 26: 256-261.

[19] McFerran, JB, McNutly, M, McKilliop, ER, Conner, TJ, McCracken, RM, Collins, DS and Allan, GM. Isolation and serological studies with infectious bursal disease virus from fowl, turkeys and ducks: demonstration of a second serotype. Avian Pathol 1980; 9: 395-404.

[20] McNulty, MS, Allan, GM and Mc Ferran, JB. Isolation of infectious bursal disease virus from turkeys. Avian Pathol 1979; 8: 205-212.

[21] Muller, H, Islam, MR and Raue, R. Research on infectious bursal disease - The past, the present, and the future. Vet Microbiol 2003; 97:153-165.

[22] Muller, H, Lange, $\mathrm{H}$ and Becht, H. Formation, characterization and interfering capacity of a small plaque mutant and of incomplete virus particles of infectious bursal disease virus. Virus Res 1986; 4: 297-309.

[23] Petek, M, D'Aprile, PN and Cancellotti, F. Biological and physicochemical properties of the infectious bursal disease virus (IBDV). Avian Pathol 1973; 2: 135-152.

[24] Rinaldi, A, Lodetti, E, Cessi, D, Lodrini, E, Cervio, G and Nardelli, L. Coltura del virus de Gumboro (IBA) su fibroblast de embrioni di pollo. Nuova Vet 1972; 48: 195-201.

[25] Rosenberger, JK, Saif, YM and Jackwood, DJ. Infectious Bursal Disease. In: Dufour-Zavala, L, Swayne, DE, Glisson, J. RJ, Pearson, E, Reed, WM, Jackwood, MW and Woolcock, PR, editors. A laboratory manual for the isolation and identification of avian pathogens 5th ed, American Association of Avian Pathologists; 2008 p. 188-190.

[26] Roy, P, Raja, A and Dhillon, AS. Counterimmunoelectrophoresis for diagnosis of infectious bursal disease: comparative efficacy of three different electrophoresis buffers. J. Appl Poult Res 2008; 17: 116-120.

[27] Skeeles, JK and Lukert, PD. Studies with an attenuated cell-culture-adapted infectious bursal disease virus: Replication sites and persistence of the virus in specific-pathogen-free chickens. Avian Dis 1980; 24: 43-47.

[28] Tsukamoto, K, Matsumura, T, Mase, M. and lmai, K. A highly sensitive, broad-spectrum infectivity assay for infectious bursal disease virus. Avian Dis 1995; 39: 575-586.

[29] Van den Berg, TP. Acute infectious bursal disease in poultry: a review. Avian Pathol 2000; 29: 175-194.

[30] Vieltiz, E. Aspects of Protection against Gumboro virus. Zoo International 1993; 16: 42-49.

[31] Yamaguchi, S, Imada, I and Kawamura, H. Growth and infectivity titration of virulent infectious bursal disease virus in established cell lines from lymphoid leukosis. Avian Dis 1981; 25: 927-935. 